\title{
The Development Mode and Innovation Mechanism of Convergence of Culture and Science: Cases from Jiangsu, China
}

\author{
Junlong $\mathrm{Wu}^{*}$ \\ Nanjing University of the Arts, China \\ Submission: November 18, 2019; Published: November 25, 2019 \\ "Corresponding author: Junlong Wu, Nanjing University of the Arts, China
}

\begin{abstract}
The convergence of culture and science has become the consensus of the government, industry and academia in China. Based on the characteristics of the convergence of culture and science in Jiangsu, China, this paper studies its development mode and innovation mechanism. It is found that the development of convergence of culture and science in Jiangsu, China is mainly manifested in two forms: supply-side convergence based on technology-driven and demand-side convergence based on market-driven, as well as several specific development mode under this two forms. The innovation mechanism of the convergence of culture and science of Jiangsu in China is mainly embodied in the collaborative innovation mechanism of technology and the business innovation mechanism of operation.
\end{abstract}

Keywords: Convergence of culture and science; Development mode; Innovation mechanism

\section{Introduction}

The $13^{\text {th }}$ five-year plan for economic and social development of the People's Republic of China proposed to promote the convergence and development of culture, science information technology, tourism, sports, finance and other industries. In recent years, the convergence of culture and science has become the consensus of the government, industry and academia in China. Many scholars have made useful explorations on this issue. Liu et al. [1] put forward the mode of deep convergence of culture and science, in which elements are coupled and interacted. Fu \& Li [2] present two modes: government-driven and enterprise practice. Peng \& Song [3] propose three mode: technology-driven, leapfrog development and government promotion. Yin [4] summaries the convergence mode of Chengdu as three forms: creativity + science, content + channel, extension + expansion. Chen [5] proposes four mode: consumption promotion, platform construction, industry chain extension and digital entertainment experience. Bi [6] divides the convergence of culture and science into six mode according to the direction, depth and form of convergence. Yi et al. [7] combine three levels of culture and explore nine convergence mode. Obviously, the convergence mode of culture and science shows diversity based on resource endowment of culture and science, so it is necessary to study the typical regional convergence mode.
In addition, the convergence of culture and science and technology has a tremendous driving force for innovation. Wang [8] proposes that the implementation of cultural and scientific innovation project should strengthen the mechanism of technological innovation driving service mode innovation, technological platform and channel innovation, collaborative innovation based on bases and projects, and development of environmental innovation. Kong [9] suggests that promotion of the convergence and innovation of culture and science should be implemented based on the non-linear relationship of cultural and science system, effective use of the rules of self-organization and other-organizations, and the core competitiveness of cultural content. Wang \& Xu [10] find that the convergence of government, industry, university and research, and the formation of regional innovation convergence network can enhance the innovation ability of culture and science field through a system dynamics model test. From current research, the convergence of culture and science is still in the stage of accelerating mutual penetration, and there is still room for further exploration of the innovation mechanism.

Therefore, this paper will first condense the development characteristics of the convergence of culture and science in Jiangsu, China in the second section, and then study its development mode and innovation mechanism in the third section and the fourth 
section, respectively. Finally, in the fifth section, targeted policy recommendations are put forward.

\section{Basic Characteristics of the Convergence of Culture and Science in Jiangsu, China}

After 40 years of rapid development after reform and opening up, Jiangsu has accumulated a good foundation for the convergence of culture and science, and the comparative advantages of cultural resources and scientific resources are outstanding. Jiangsu is a province with rich cultural resources and profound cultural production factors. The superiority of excellent cultural resources provides good cultural resources endowment conditions for the convergence of culture and science. At the same time, Jiangsu has strong scientific strength and first-class scientific innovation strength. The number of scientific institutions has reached 200,000 , the number of professional and technical personnel is close to 1.2 million, the annual average $R \& D$ investment is about 450 billion RMB, the annual average patent application maintains at the level of $400,000-500,000$, the grant of patent rights is maintained at the level of 200,000-250,000, and the output value of high-tech industry has reached the level of 6 trillion RMB. The development of science has laid a solid foundation for promoting the convergence of culture and science.

Jiangsu has built three national-level cultural and scientific convergence bases, and the provincial cultural parks or bases and incubators of cultural science enterprises rank in the forefront of the country in quantity and scale. For example, Nanjing focuses on four major areas: digital audio-visual entertainment, modern creative design, new network media, intelligent tourism and leisure; Wuxi vigorously develops digital content industry represented by digital film and television; Changzhou promotes the convergence of software design, animation and creative design, digital entertainment and other industries.

In recent years, the system and mechanism of the convergence of culture and science in Jiangsu have been continuously improved, and the policy environment has been continuously optimized.
The provincial government has promulgated "Policies for the management of cultural and scientific enterprises" and "Policies for the management of cultural and scientific industrial parks", and has identified 32 provincial cultural and scientific industrial parks and 195 provincial cultural and scientific enterprises. Last year, Jiangsu has issued "Twenty policy measures to promote the convergence of culture and science", which encourages enterprises as the main entity of implementing policies and measures for the convergence of culture and science.

The impact of the convergence of culture and science has begun to show. The rapid rise of new cultural business type using digital, networked and intelligent high-tech has provided strong technical support for the continuous promotion of high-quality cultural development in Jiangsu. At present, Jiangsu cultural enterprises have entered the core cultural fields such as news information service, content creation and production, creative design service, cultural communication service and other cultural related fields such as cultural auxiliary production and intermediary service, cultural equipment production, cultural consumption terminal production. It has initially formed the leading industries of convergence of culture and science such as radio and television media, publishing and distribution, digital content of film and television, game animation, cultural expositions and exhibitions.

Jiangsu is one of the regions with the strongest comprehensive economic strength and the most vigorous development in China. In 2018, the total economic output exceeded 9 trillion RMB, the per capita GDP exceeded 100,000RMB, and the living standards of residents continued to improve. At the same time, high and new technologies such as mobile internet, big data and intelligent manufacturing have accelerated their penetration into all aspects of cultural product creation, production and dissemination. Digital cultural products and services can meet the cultural needs of residents in a more open, shared and convenient way of diffusion. Cultural enterprises grow rapidly and show great potential to achieve the convergence of culture and science in depth.

\section{Development Mode of the Convergence of Culture and Science in Jiangsu, China}

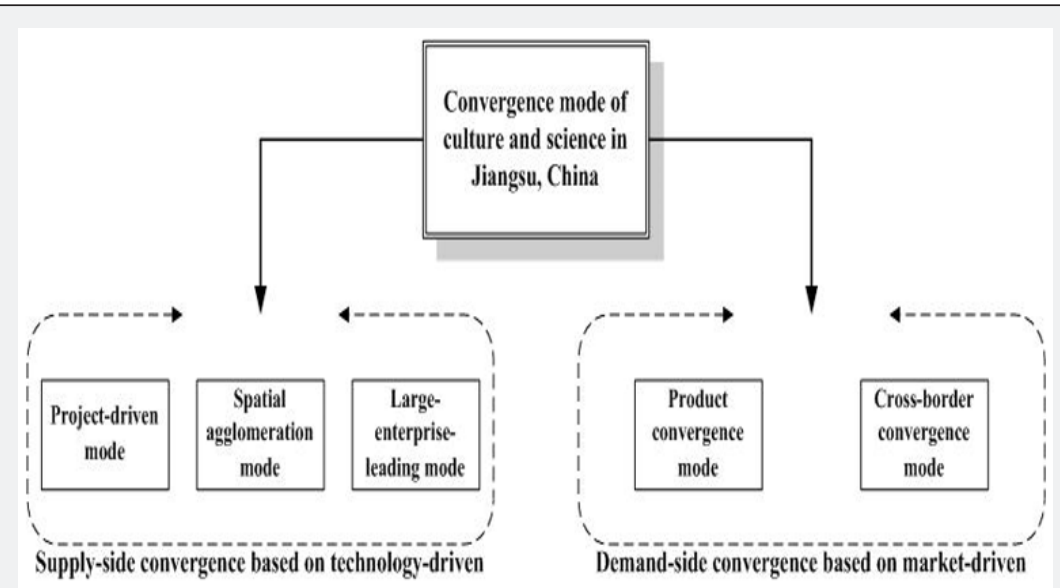

Figure 1: The form and model of the convergence of culture and science. 
From the perspective of market supply and demand, industrial convergence can be divided into supply convergence and demand convergence [11-13]. From the perspective of production and consumption, it can be divided into technology-driven convergence and market-driven convergence $[14,15]$. From the practice of Jiangsu, China, the occurrence of the convergence of culture and science usually starts from the actual conditions of cultural endowment, scientific elements and the level of economic and social development. Its convergence mode is mainly manifested in two forms: supply-side convergence based on technology-driven and demand-side convergence based on market-driven, as well as several subschema belonging to two major forms, as shown in Figure 1.

In most cases, the convergence of culture and science in Jiangsu is mainly driven by technological factors or market factors alone, but there are also cases that two factors drive together. This means that the power to promote the convergence of culture and science in Jiangsu is not limited to technology or terminal consumer market, both of which can promote the convergence.

From the perspective of the main body of promoting the convergence of culture and science, there are five categories: natural persons, cultural and scientific enterprises, consumers, intermediaries and governments. Natural persons provide original wisdom for the convergence of culture and science mainly by exerting their own cultural or scientific capital. Cultural and scientific enterprises promote the convergence of scientific elements into cultural development by aggregating cultural and scientific capital. Consumers' demand for cultural products and services with more scientific content forms the traction to guide enterprises' production and promote market supply. All kinds of intermediary organizations, including intellectual property transactions and technology supply intermediaries, are the bridges and media to promote the convergence of culture and science. The role of government is not only the provider of public knowledge and scientific products and services, but also the maintainer of the institutional environment for the convergence of culture and science.

The penetration of science into culture has led to supplyside convergence based on technology-driven. With the increase of the spillover effect of science and technology, the technology spillover of technology co-evolution among different industries will also increase. Therefore, the existing scientific technology in culture will be replaced by new scientific technology, and ultimately, the existing value chain of culture will be broken. From the perspective of the characteristics of the convergence of different industries, science will become an important driving force for the convergence of culture and science. The technologydriven supply-side convergence of culture and science in Jiangsu is mainly manifested in project-driven mode, spatial agglomeration mode and large-enterprise-leading mode.

The project-driven mode refers to the industrial convergence mode of cultural development driven by technological innovation and transformation, which is guided by meeting the needs of cultural technology and links cultural development with scientific development through the implementation of scientific innovation projects by the government. Based on this model, government departments regard science as public goods, and use public financial funds to embedding science into culture in the way of projects, so as to improve the scientific content and added value of cultural products and services, and promote the convergence of culture and science. This model is the most direct way to promote science to intervene into culture, and it also has obvious characteristics of government participation.

Spatial agglomeration mode refers to the mode that cultural resources and scientific elements gradually gather in the same regional space, thus generating the agglomeration effect of attracting related economic activities to the regional space. Jiangsu's three national-level cultural and scientific convergence bases are located along the Yangtze River, especially in Nanjing, Wuxi, Changzhou and other cities south of the Yangtze River. The spatial agglomeration trend is more obvious and the agglomeration effect is significant.

Large-enterprise-leading mode refers to the mode in which cultural organizations (cultural enterprises) with large scale and strong market power play their technological advantages, integrate scientific elements into the process of production and trade of cultural products, and lead enterprises in the industry to use relevant scientific resources on a large scale. large -enterprise-leading mode highlights the dominant position of cultural enterprises in industrial convergence and reflects the enhancement of independent R\&D capabilities of cultural enterprises.

From the perspective of demand-side convergence based on market-driven, industry convergence be the result of changing consumer preferences. Consumers try to meet new cultural consumption needs in market transactions. In practice, technology-driven supply-side convergence triggers the convergence of culture and science, while market-driven demandside convergence strengthens the convergence of culture and science. Demand-side convergence based on market-driven of culture and science in Jiangsu is mainly manifested in product convergence mode and cross-border convergence mode.

Product convergence mode refers to the development mode of "culture + science" which takes market demand as the guidance and uses science to change the characteristics and functions of original cultural products and services and realize product innovation, thus leading to the differentiation of the original product form. The main driving force of product innovation is the rapid diffusion of science into culture. Cross-border convergence mode refers to the market demand-oriented independent growth of scientific elements and creative, capital, talent, information and other elements of culture and other industries to form the so-called "culture + Science + other industries". Cross-border convergence is not only the convergence of culture and science, but 
also the convergence of many industries. It blurs the boundaries of science, culture and other industries, and makes the factors of production and resources of various industries recombine to form a new industrial form. In Jiangsu, a typical example is Changzhou's cultural and scientific tourism industry.

\section{Innovative Mechanism of Convergence of Culture and} Science

The innovation mechanism of the convergence of culture and science in Jiangsu is mainly embodied in technology innovation and business management innovation. As far as technological innovation mechanism is concerned, it is mainly the collaborative innovation in the field of culture and science that provides technological supply space for their development.

Based on the framework of "communication-coordinationcooperation-coordination", collaborative innovation involves a complex network system in which information, technology, knowledge and other resources are exchanged and integrated [16]. The essence of synergy is that the elements of the system coordinate with each other so as to exert the synergistic effect [17]. Therefore, collaborative innovation is to promote innovators to give full play to their respective capabilities and advantages; to integrate knowledge, resources, behavior and performance in an all-round way; to realize the sharing of innovative and mutually beneficial knowledge and technology, the optimal allocation of resources, the optimal synchronization of actions and the high level of system matching; and then to achieve the non-linear effect of the system superposition beyond the sum of the original values of the elements in innovation [18]. Collaborative innovation in the convergence of culture and science means that innovation does not occur on a single side, not only by using existing knowledge, ability, technology and resources in the field of culture or science to innovate, but by means of specific collaborative ways to complete the whole process from putting forward ideas to producing products.

From the current practice of collaborative innovation in the convergence of culture and science in Jiangsu, it is needed to overcome the technical competences owned by different industry [19], technical path $[20,21]$, technical absorptive capacity $[22,23]$, industrial recipes [24] and other obstacles to achieve synergy between them. First, the field of science has evolved over a long period of time, and so is culture. Whether in the field of culture or science, there is a certain technical competence owned by culture and science. Therefore, culture does not have the basis for directly accepting relevant technologies in the field of science in the process of convergence. Secondly, in the process of the convergence of culture and science, the emergence of collaborative innovation is related to the ability of culture to absorb relevant technologies in the field of science. Culture must have a certain level of absorptive capacity to science in order to identify the relevant technology in the field of science and apply it to its own development. If culture cannot get rid of the dependence of technical path generated by its own long-term development, it will be very difficult to improve the technological absorptive capacity. Thirdly, the collaborative innovation of culture and science is also related to the industrial recipes between them. There are differences in industrial recipes between culture and science. The greater the gap between industrial recipes between culture and science, the greater the obstacles to collaborative innovation in the process of convergence and development. This is because different ways of resource investment and R\&D methods may be adopted in collaborative innovation in the cultural and scientific fields. Therefore, the difference of industrial recipes brings a certain degree of uncertainty to the collaborative innovation between them.

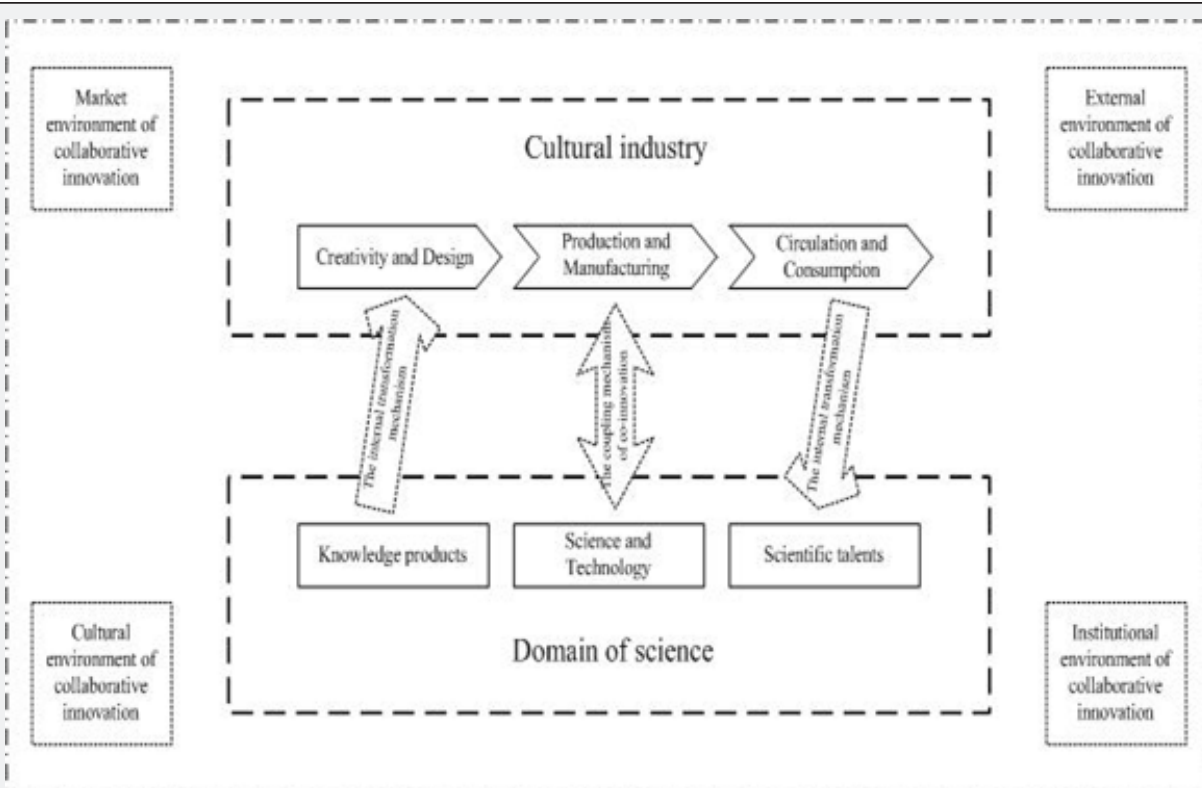

Figure 2: The collaborative innovation mechanism for the convergence of culture and science. 
The collaborative innovation mechanism for the convergence of culture and science in Jiangsu constructs the inflow and outflow mechanism of knowledge and technology between science and culture to break down the obstacles in technical competences, technical path, technical absorptive capacity and industrial recipes between the two industries. There are three main mechanisms: the internal transformation mechanism of culture from acquiring knowledge and technology in the field of science, the external transformation mechanism of knowledge and technology transfer from science to culture, and the coupling mechanism of coinnovation in the convergence of culture and science, as shown in Figure 2.

The internal transformation mechanism of culture from acquiring knowledge and technology in the field of science is an innovative mechanism for culture to enrich its own knowledge and technological reserves by absorbing knowledge and technology in the field of science, thereby improving the scientific content of products and services. Specifically, this mechanism can be achieved through the following modes: culture directly purchases and uses related technologies from the scientific field; culture purchases technology use rights from the scientific field (intellectual property rights); culture contracts technological innovation or R\&D needs to the scientific field; culture (enterprises) acquires related technologies by merging related scientific fields (enterprises) through capital operation; and culture directly. Obtain human capital from the scientific field to master relevant technology.

The external transformation mechanism of knowledge and technology transfer from science to culture is an innovative element projecting to culture in the field of science, and it is an innovative mechanism that science actively seeks technology supply from culture. This mechanism can function through the following specific modes: technology in the field of science is exported to culture (sold); technology in the field of science is granted the right to use technology in the field of science and corresponding benefits are obtained; technology or technology in the field of science is provided to culture but the cost of technology research and development is borne by the government in a rewarding way.

The coupling mechanism of co-innovation in the convergence of culture and science is a mechanism that combines the inflow and outflow of knowledge and technology from both sides and jointly develops technological innovation in the field of culture and science. In the field of culture and science, technology cooperation platform, technology network and innovation ecosystem should be constructed to share technology; in the field of culture and science, cultural enterprises should be established to promote the commercialization of science; and in the field of culture and science, technology research and development should be carried out jointly by means of venture capital.

As far as business management innovation mechanism is concerned, is mainly to replace the traditional management mode, management technology and management means with innovative management mode, innovative management technology and innovative management means to meet consumer demand and create new commercial value based on the new cultural and scientific format.

The collaborative innovation mechanism of the convergence of culture and science in Jiangsu emphasizes the innovation of supply side or production side, but it cannot be ignored that the influence of demand side or consumption side on innovation mechanism exists outside the supply or production system. Therefore, considering the role of demand side or consumer side in cultural and scientific integration innovation, another innovation mechanism is format innovation mechanism.

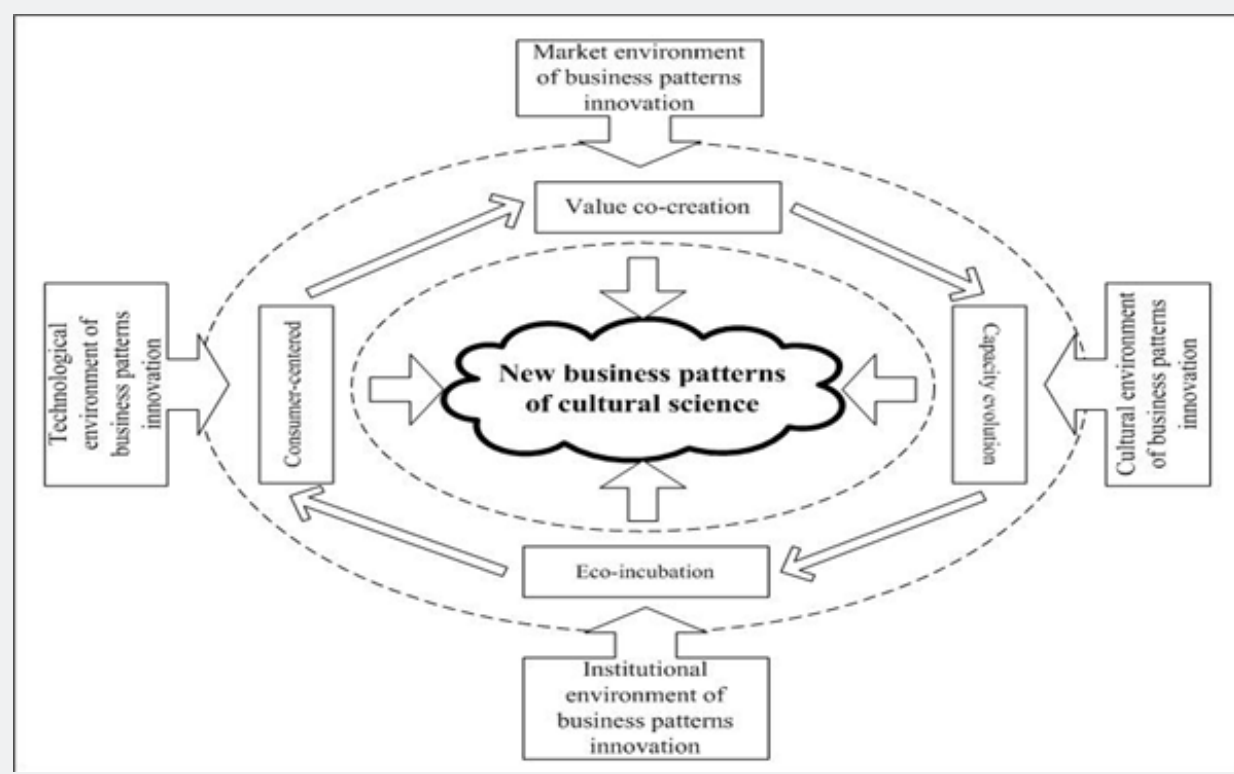

Figure 3: The innovation mechanism of business patterns for the convergence of culture and science. 
Business patterns refers to the specific needs of specific consumers, according to certain strategic objectives, selectively using the business structure of commodities, store location, shop size, shop form, price policy, sales methods, sales services and other business means to provide sales and services of the type of service form [25]. Business patterns innovation is to update and change the service form of typification. From the perspective of strategic management, patterns innovation mechanism is a mechanism to discover the commercial value of new cultural products or services through the integration of culture and science and based on market exploration and verification. Therefore, patterns innovation mechanism is essentially an important mechanism to create new commercial value. Obviously, the process of business innovation of cultural and scientific integration necessarily includes the behavior of business information recognition, trial-and-error learning and organizational adaptation of industrial organizations due to the uncertainty and complexity of potential market of new cultural products and services caused by the interplay of culture and science; the result of business innovation of cultural and scientific integration is contained in content production, VR new media and creative design. New business value in new patterns such as digital cloud services. The innovative mechanism of the integration of culture and Science in Jiangsu is mainly manifested in four aspects: consumer-centered mechanism, value co-creation mechanism, capacity evolution mechanism and eco-incubation mechanism, as shown in Figure 3.

Consumer-centered mechanism means that business innovation aiming at satisfying consumers' value should deal with the uncertainty and complexity of potential market according to the information of business demand side. Only when the new cultural science industry provides cultural and scientific products and services conforming to the needs of consumers, can it produce higher commercial value. Therefore, it is an important way to realize the consumer-centered mechanism to identify potential cultural consumption demand, recognize consumer behavior and observe consumer consumption process by using technical means such as consumption data analysis.

The value co-creation mechanism emphasizes that neither consumers nor cultural or scientific industry organizations should unilaterally be the determinants of the commercial value of the new business pattern in the innovation of cultural and scientific formats in Jiangsu. The commercial value of the new business pattern should be determined jointly by consumers and cultural or scientific industry organizations through close cooperation, so that consumers can participate in the process of creating new commercial values. Obviously, the value co-creation mechanism can also effectively reduce the risks brought by market uncertainty and complexity of patterns innovation, so that cultural or scientific industry organizations can carry out patterns innovation under the premise of fully understanding consumer needs in cooperation.

Capacity evolution mechanism provides decision-making basis for business innovation, and it is a mechanism for cultural or scientific industrial organizations to re-develop business value creation in order to adapt to changing consumer demand. The process of acquisition of knowledge and technology indispensable to form innovation by cultural or scientific industrial organizations is embodied in the evolution of form innovation ability, mainly in the form of "trial and error-learning". The R\&D departments of cultural or scientific industrial organizations adjust their internal knowledge and technology reserves by introducing human capital or knowledge capital and realize the process of creating new business value through repeated R\&D processes.

Eco-incubation mechanism is a mechanism for cultural or scientific industrial organizations to expand the business value creation partnership of cultural or scientific convergence, to share technological basis and business value, and to incubate and cultivate the ecological system. In the process of cultural and scientific convergence, cultural or scientific industrial organizations increasingly rely on mutual interaction and cooperation to acquire relevant knowledge and technology, because the realization of new business opportunities and values depends on other organizations among industrial organizations to provide relevant cultural and scientific products and services for consumers. From a practical point of view, business innovation often occurs in the ecosystem of cultural or scientific industrial organizations. The huge ecosystem of cultural and scientific convergence enables more cultural or scientific industrial organizations to participate in industrial innovation, or to provide solutions for new cultural and scientific products and services, or to provide complementary knowledge and technology, or to provide small micro-cultural or scientific industrial organizations with opportunities for industrial innovation.

\section{Research Conclusion and Policy Implications}

This paper studies the development mode and innovation mechanism of the convergence of culture and science based on the practical characteristics in Jiangsu, China. It is found that the development of convergence of culture and science in Jiangsu, China is mainly manifested in two forms: supply-side convergence based on technology-driven and demand-side convergence based on market-driven, as well as several specific development mode under this two forms. The innovation mechanism of the convergence of culture and science of Jiangsu in China is mainly embodied in the collaborative innovation mechanism of technology and the business innovation mechanism of operation.

Based on the analysis of the convergence of culture and science, this paper puts forward the following policy implications. Firstly, the government could play an important public role to further improve the service system for cultural and scientific convergence. Culture and science have certain attributes of public goods. The government has the space to play its public functions and promote the convergence of culture and science, especially in promoting public cultural services and scientific services. The government can organize training courses for senior managers of cultural enterprises to foster an atmosphere in which managers of cultural enterprises take the initiative to integrate culture and science. 


\section{Annals of Social Sciences \& Management studies}

The government can establish a theoretical base, technology base, think tank and routine consultation service mechanism for the convergence of culture and science based on scientific experts to provide targeted scientific consultation services for all kinds of cultural enterprises. The government should reduce the administrative control related to the convergence of culture and science and reduce the institutional cost of the transformation of scientific achievements into cultural fields.

Secondly, the comparative advantages of cultural and scientific resources should be brought into full play to promote collaborative innovation in key areas. Looking at the reality of collaborative innovation in the convergence of culture and science, it is not difficult to find that there is a certain degree of inconsistency in resources, knowledge and technology between a region's scientific field and culture, and the mechanism of collaborative innovation between the two needs to be further strengthened. Therefore, the synergistic innovation of the convergence of regional culture and science should mainly focus on the field of comparative advantage.

Thirdly, the construction of supporting mechanism for cultural innovation and entrepreneurship will promote the development of new business patterns of convergence of culture and science. The new business patterns is the embodiment and result of cultural and scientific innovation. In order to promote the development of new business patterns, the key is to build a supporting mechanism for cultural innovation and entrepreneurship. Relevant institutions should promote the penetration of science into culture, provide support from bank credit, listing financing and talent introduction to cultural enterprises, and promote innovative achievements through public cultural service channels. To enhance the confidence of cultural enterprises in innovation, relevant institutions should implement different supporting policies, mainly from the system supply, fiscal policy, standard-setting and other aspects to support the new business patterns of cultural science. The whole society should break down the obstacles to the flow of scientific talents to culture and implement the support plan for innovative talents in cultural science, and guide a certain number of scientific talents to flow to the cultural industry and accelerate the release of the dividend of scientific talents in the cultural field.

\section{Acknowledgements}

The authors acknowledge the financial support of the Jiangsu Province Social Sciences Applied Research Excellent Project (17SYB-088) by Jiangsu Association of Philosophical and Social Sciences.

\section{Competing Interests}

The authors have no competing interests to declare.

\section{References}

1. Liu XH, Zhou HR, Chen G (2013) Research on Promoting to Combine Culture and Science and Technology Deeply of Shanghai. Scientific Development 9: 49-59.

2. Fu CW, Li GD (2015) The supporting role of science and technology in culture during the 13th Five-year Plan period. Journal of Ocean University of China (Social Sciences) 6: 61-65.
3. Peng YK, Song YY (2013) Theoretical research on the convergence of culture and science and technology from the perspective of industrial convergence mechanism. Management and Administration 8: 75-78.

4. Yin $H$ (2013) Path selection of the convergence of modern urban culture and science from the perspective of culture: A case study of Chengdu city, Sichuan province. Journal of Sichuan Administration Institute 6: 78-81.

5. Chen QH (2013) Research on the convergence model of culture and science in Jiangsu, China. Reality Only 3: 54-55.

6. Bi J (2013) Research on scientific Beijing strategy from the perspective of science and culture. Journal of Commercial Economics 2013(33): 142-143.

7. Yi T, Jiang GH, Huang L (2015) Discussion about the basic mode of the convergence of culture and technology. Forum on Science and Technology in China 5: 122-127.

8. Wang ZG (2012) Promoting the innovation of cultural science and strengthening the convergence of culture and science. Qiushi 2: 54-56.

9. Kong SH (2014) Research on the innovation mechanism of cultural science convergence in the new media environment. Shanghai Culture 10: 4-8.

10. Wang C, Xu G (2016) Research on innovation mechanism of cultural science and technology convergence from the perspective of regional innovation network. Hainan Finance 4: 24-30.

11. Bröring S, Cloutier LM, Leker J (2006) The front end of innovation in an era of industry convergence: evidence from nutraceuticals and functional foods. R\&D Management 36(5): 487-498.

12. Lee GK (2007) The significance of network resources in the race to enter emerging product markets: The convergence of telephony communications and computer networking, 1989-2001. Strategic Management Journal 28(1): 17-37.

13. Curran CS, Leker J (2011) Patent indicators for monitoring convergence-examples from NFF and ICT. Technological Forecasting \& Social Change 78(2): 256-273.

14. Hacklin, F, Marxt C, Fahrni F (2009) Coevolutionary cycles of convergence: an extrapolation from the ICT industry. Technological Forecasting \& Social Change 76(6): 723-736.

15. Kim E, Cho Y, Kim W (2014) Dynamic patterns of technology convergence in printed electronics technologies: patent citation network. Scientometrics 98(2): 975-998.

16. Serrano V, Fischer T (2007) Collaborative innovation in ubiquitous systems. Journal of Intelligent Manufacturing 18(5): 599-615.

17. Haken H (2004) Synergetics: Introduction and advanced topics. Springer-Verlag, Berlin, Germany.

18. Chen J, Yang YJ (2012) Theoretical basis and content for collaborative innovation. Studies in Science of Science 30(02): 161-164.

19. Fai F, Von Tunzelmann N (2001) Industry-specific competencies and converging technological systems: evidence from patents. Structural Change \& Economic Dynamics 12(2): 141-170.

20. Teece DJ, Pisano G, Shuen A (1997) Dynamic capabilities and strategic management. Strategic Management Journal 18(7): 509-533.

21. Greener I (2002) Theorizing path dependency: how does history come to matter in organizations? Management Decision 40(6): 614-619.

22. Cohen WM, Levinthal DA (1990) Absorptive capacity: a new perspective on learning and innovation. Administrative Science Quarterly 35(1): 128-152.

23. Bröring S, Leker J (2010) Industry Convergence and Its Implications for the Front End of Innovation: A Problem of Absorptive Capacity. Creativity \& Innovation Management 16(2): 165-175. 


\section{Annals of Social Sciences \& Management studies}

24. Day GS, Schoemaker PJ (2000) Wharton on managing emerging technologies. Wiley, New York, USA.

This work is licensed under Creative Commons Attribution 4.0 License

DOI: 10.19080/ASM.2019.04.555646
25. Xiao GS (2003) Revolution of business pattern of food retailing sector Science and Technology of Food Industry 11: 4-5.

Your next submission with Juniper Publishers
will reach you the below assets
- Quality Editorial service
- Swift Peer Review
- Reprints availability
- E-prints Service
- Manuscript Podcast for convenient understanding
- Global attainment for your research
- Manuscript accessibility in different formats
( Pdf, E-pub, Full Text, Audio)
- Unceasing customer service
Track the below URL for one-step submission
https://juniperpublishers.com/online-submission.php

